\title{
Resonant Full-Bridge Synchronous Rectifier Utilizing 15 V GaN Transistors for Wireless Power Transfer Applications Following AirFuel Standard Operating at 6.78 $\mathrm{MHz}$
}

Jensen, Christopher Have Kiaerskou; Spliid, Frederik Monrad; Hertel, Jens Christian; Nour, Yasser; Zsurzsan, Tiberiu-Gabriel; Knott, Arnold

\section{Published in:}

Proceedings of 2018 IEEE Applied Power Electronics Conference and Exposition

Link to article, DOI:

10.5281/zenodo.1220264

Publication date:

2018

Document Version

Peer reviewed version

Link back to DTU Orbit

Citation (APA):

Jensen, C. H. K., Spliid, F. M., Hertel, J. C., Nour, Y., Zsurzsan, T-G., \& Knott, A. (2018). Resonant Full-Bridge Synchronous Rectifier Utilizing $15 \mathrm{~V}$ GaN Transistors for Wireless Power Transfer Applications Following AirFuel Standard Operating at $6.78 \mathrm{MHz}$. In Proceedings of 2018 IEEE Applied Power Electronics Conference and Exposition (pp. 3131-3137). IEEE. https://doi.org/10.5281/zenodo.1220264

\section{General rights}

Copyright and moral rights for the publications made accessible in the public portal are retained by the authors and/or other copyright owners and it is a condition of accessing publications that users recognise and abide by the legal requirements associated with these rights.

- Users may download and print one copy of any publication from the public portal for the purpose of private study or research.

- You may not further distribute the material or use it for any profit-making activity or commercial gain

- You may freely distribute the URL identifying the publication in the public portal 


\title{
Resonant Full-Bridge Synchronous Rectifier Utilizing $15 \mathrm{~V}$ GaN Transistors for Wireless Power Transfer Applications Following AirFuel Standard Operating at $6.78 \mathrm{MHz}$
}

\author{
Christopher Have Kiaerskou Jensen, Frederik Monrad Spliid, Jens Christian Hertel, \\ Yasser Nour, Tiberiu-Gabriel Zsurzsan, Arnold Knott \\ Department of Electrical Engineering, Technical University of Denmark \\ 2800 Kgs. Lyngby, Denmark \\ Email: s144042@student.dtu.dk, \{frmsp,chrhert, ynour, tgzsur, akn\}@elektro.dtu.dk
}

\begin{abstract}
Connectivity in smart devices is increasingly realized by wireless connections. The remaining reason for using connectors at all is for charging the internal battery, for which wireless power transfer is an alternative. Two industry standards, AirFuel and Qi, exist to support compatibility between devices. This work is focusing on the AirFuel standard, as it is operating at a higher frequency $(6.78 \mathrm{MHz})$, than the Qi standard, and therefore allows smaller passive components, including the coupling coils. Whereas gallium-nitride (GaN) devices are being widely used on the transmitter ( $\mathrm{Tx}$ ) side, this work uses low voltage GaN transistors on the receiver $(\mathbf{R x})$ side to allow synchronous rectification and soft switching, thereby achieving high efficiency. After analyzing adequate Class-DE rectifier topologies, a ClassDE full-bridge $5 \mathrm{~W}$ rectifier using $15 \mathrm{~V}$ GaN transistors are designed and implemented. The experimental results show an efficiency above $80 \%$ over a wide operating range and a peak efficiency of $89 \%$, at an arbitrary alignment of $T x$ and $R x$ coils with $3 \mathrm{~cm}$ distance between them.
\end{abstract}

Index Terms-Wireless power transfer, AirFuel, synchronous rectification, resonant circuit, soft-switching, GaN devices.

\section{INTRODUCTION}

In recent years, the attention to wireless charging technologies for consumer applications, as shown in Fig. 1, has grown dramatically. Avoiding the connectors in smartphones and tablets allow for a further increase in their robustness (e.g. water proof cases) and gives more space for energy storage in the battery to increase the battery life. Therefore, two standards were created; Qi [1] and AirFuel [2]. Research activities, addressing the lower frequency $(87-205 \mathrm{kHz})$ Qi standard [3]-[7] and the higher frequency (6.78 MHz) AirFuel standard [8]-[18], grew as well. Some work [19], [20] are targeting both standards and other work [21], [22] reported operation outside those standards. Higher frequencies promise size reduction of passive components. In terms of wireless charging applications, this results in smaller transmitter (Tx) and receiver $(\mathrm{Rx})$ coils. Therefore this work focuses on the AirFuel standard. Gallium nitride $(\mathrm{GaN})$ devices are used in [12], [15], [18] to reduce switching losses on the Tx side. Synchronous rectifiers, typically used in high power applications [23], [24], address the conduction losses on the Rx side in [3], [7], [13]. This work combines these two advantages on the Rx side with a synchronous rectifier based on GaN devices, fulfills the AirFuel standard [2] and addresses the specification in table I. This paper presents the work of [25].
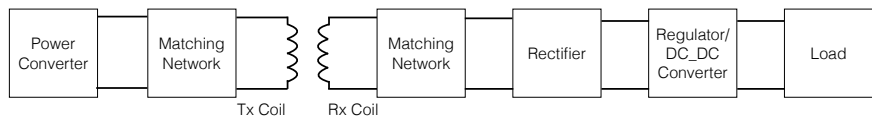

Fig. 1. Block diagram of the elements in a wireless power transfer (WPT) system

TABLE I

DESIGN SPECIFICATIONS

\begin{tabular}{|l|l|}
\hline Output power $P_{\text {out }}$ & $5 \mathrm{~W}$ \\
\hline Output voltage $V_{\text {out }}$ & $5 \mathrm{~V}$ \\
\hline Operating frequency $f_{\text {sw }}[2]$ & $6.78 \mathrm{MHz}$ \\
\hline
\end{tabular}

\section{TOPOLOGY SELECTION}

Synchronous rectification for WPT is being researched, as it is a potential way to overcome the losses associated with diodes, which are currently used in WPT systems. Other work such as [3], [4], [7], [13], [14], [26]-[28] look into ways to implement and optimize control schemes for synchronous rectifiers.

This work uses a comparator to sense the voltage across the synchronous rectifier, as shown in Fig. 2 based on [25]. To overcome propagation delay of the gate driver, a delay is implemented between the comparator and the gate driver. This helps correct the delay of the last period in the next switching period, which is tuned to achieve soft switching.

Resonant topologies [10], [14], [16], [17], [29] are very promising for wireless charging applications, as they allow precise impedance matching to the $\mathrm{Tx}$ and $\mathrm{Rx}$ coils and simultaneously provide high energy efficiency due to their ability to soft-switch the power devices. 


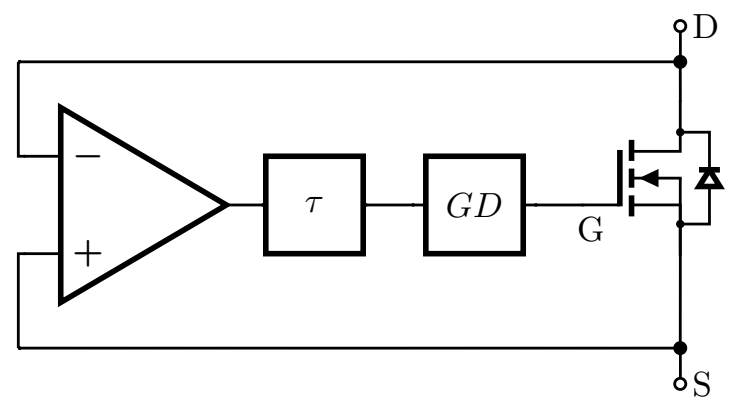

Fig. 2. Block diagram of the synchronous rectification circuit. $\tau$ is delay compensation and GD is the gate driver.

Whereas [10], [14], [16], [17], [29] use the Class-E topology to avoid high-side switches and therefore come with a high voltage stress across the power semiconductor, [30], [31] document the Class-DE topology and its corresponding highside gate driver [32], [33] as alternative. Within the currentdriven Class-DE rectifier family, Fig. 3 shows three members.

For the implementation in this work, each of the diodes is replaced with a comparator-transistor combination shown in Fig. 2.

Three topologies were investigated: the Class-DE halfbridge rectifier described in Fig. 3a [34] , a Class-DE fullbridge rectifier based on the half-bridge in Fig. $3 b$ and the half-wave Class-DE low dv/dt rectifier described in Fig. 3c [35]. These three topologies were simulated in LTspice with synchronous rectification instead of diodes. To find the transistor with the best performance for the specifications, multiple transistors where analyzed using figures of merit (FOM).

\section{A. Transistor FOM Analysis}

With the help of figures of merit, see (1) - (3), several potential power devices are investigated based on their datasheet parameters [36]-[41]. The result of the investigation is shown in table II.

$$
\begin{aligned}
& F O M_{1}=Q_{I S S} \cdot R_{D S o n} \\
& F O M_{2}=Q_{G D} \cdot R_{D S o n} \\
& F O M_{3}=Q_{O S S} \cdot R_{D S o n}
\end{aligned}
$$

The $\mathrm{FOM}_{2}$ says something about the frequency range the device can operate in, were $Q_{G D}$ is the gate-drain charge, but the focus is on the input characteristics $\mathrm{FOM}_{1}$ and the output characteristics $\mathrm{FOM}_{3}$. $Q_{I S S}$ and $Q_{O S S}$ are the input charge and output charge of a transistor respectively. $Q_{I S S}$ is found from the datasheet $Q_{G}$ vs. $V_{G S}$ plots for the given drain-source. Some of the datasheets do not show the plot for $5 \mathrm{~V}$ drain-source voltage, in which case $6 \mathrm{~V}$ or $4.5 \mathrm{~V}$ is used. $Q_{O S S}$ is approximated by integrating output capacitance $C_{O S S}$ in the full drain-source voltage range. This is important as the capacitances vary with voltage. $R_{D S o n}$ is the resistance from drain to source when the transistor is in the ON-state.

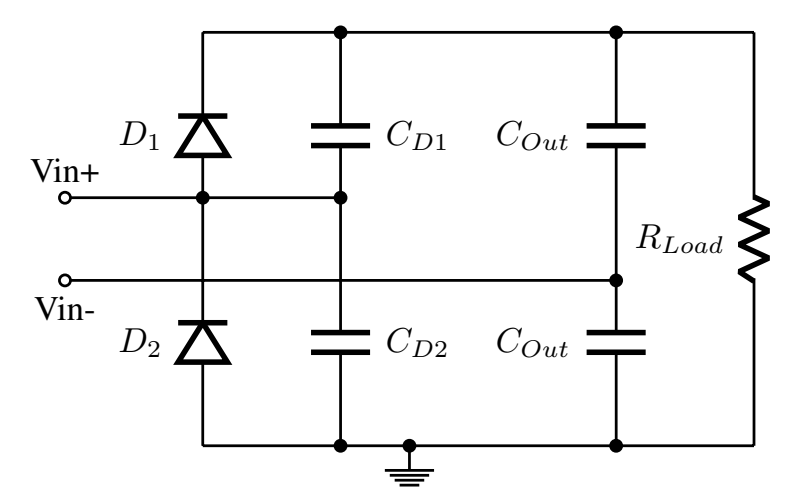

(a)

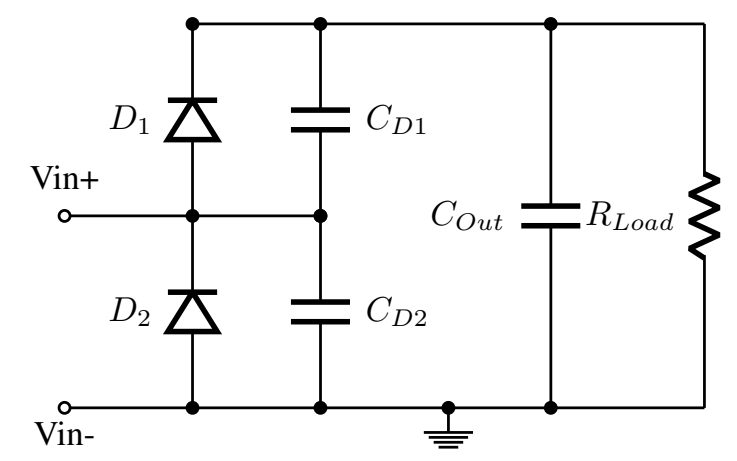

(b)

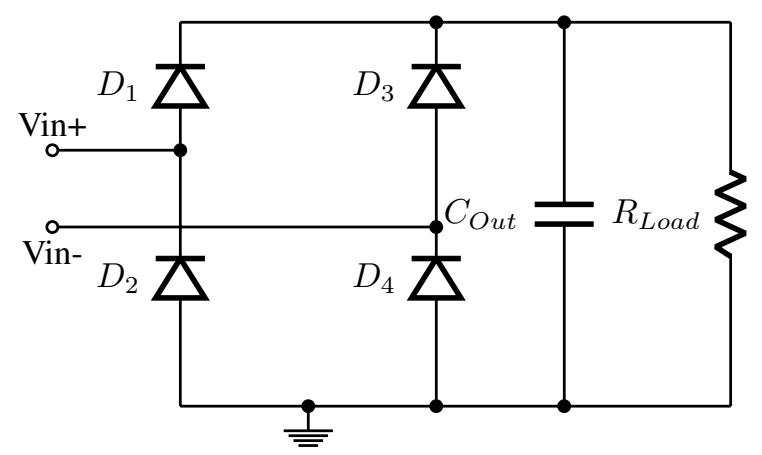

(c)

Fig. 3. Current driven soft-switching rectifier circuits. (a) is the Class-DE half-bridge rectifier, (b) the Class-DE full-bridge rectifier and (c) the halfwave Class-DE low dv/dt rectifier.

This method of evaluating transistors based on their FOM has also been done in works like [42].

Comparing the GaN EPC2040 [36] device in table II with the silicon (Si) based devices [37]-[39], [41], the GaN device is superior by a factor of 6 and 3 with respect to $\mathrm{FOM}_{1}$ and $\mathrm{FOM}_{3}$ and therefore chosen. A visualization of the transistor FOM can be seen in Fig. 4.

$$
\begin{gathered}
I_{\text {out }}=\frac{I_{m}}{2 \pi} \rightarrow I_{m}=6.28 \mathrm{~A} \\
V_{\text {out }}=\frac{I_{m}}{\omega\left(C_{D 1}+C_{D 2}\right)} \rightarrow C_{D 1}+C_{D 2}=\frac{I_{m}}{V_{\text {out }} \cdot \omega} \\
\rightarrow C_{D 1}=C_{D 2}=14.75 \mathrm{nF}
\end{gathered}
$$


TABLE II

TRANSISTOR SELECTION BASED ON FOM1 AND FOM3 BASED ON DATA FROM [36]-[41]

\begin{tabular}{|l|r|r|r|r|r|r|}
\hline Transistors: & Voltage Rating [V] & $R_{D S o n}[\mathrm{~m} \Omega]$ & $Q_{\text {iss }}[\mathrm{pC}]$ & $Q_{\text {oss }}[\mathrm{pC}]$ & $F O M_{1}[\mathrm{pVs}]$ & $F O M_{3}[\mathrm{pVs}]$ \\
\hline EPC2040 $(\mathrm{GaN})[36]$ & 15 & 28 & 745 & 357 & 20.86 & 9.996 \\
\hline SiUD412ED (Si) [38] & 12 & 340 & 500 & 102 & 170 & 34.68 \\
\hline Si4838DY (Si) [39] & 12 & 3 & 45000 & 15717 & 135 & 47.15 \\
\hline Si2342DS (Si) [40] & 8 & 17 & 10500 & 2508 & 178.5 & 42.63 \\
\hline DMN1260UFA (Si) [41] & 12 & 366 & 1050 & 211 & 384.3 & 77.35 \\
\hline Si1050X (Si) [37] & 8 & 86 & 7900 & 1277 & 679.4 & 109.83 \\
\hline
\end{tabular}

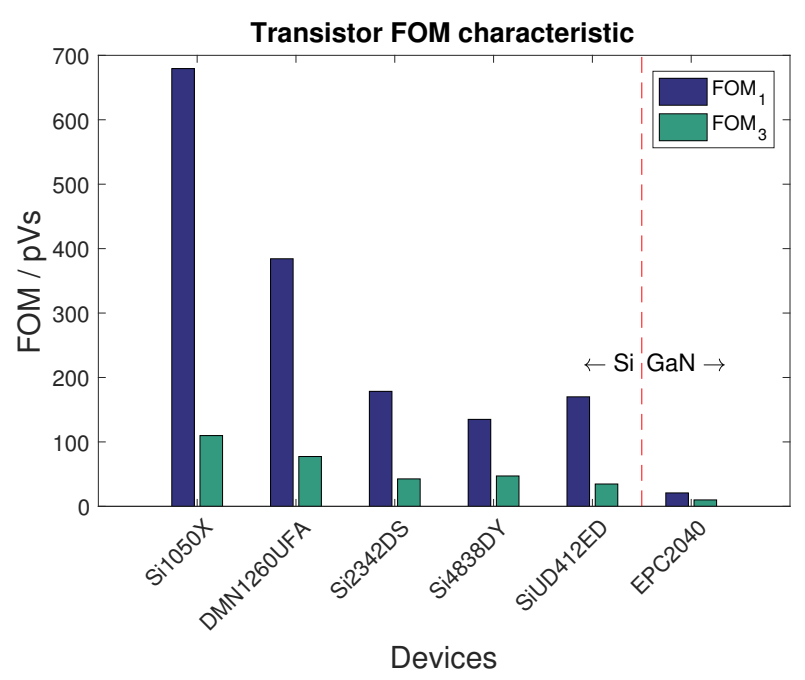

Fig. 4. Visualization of the transistors FOM values

The method presented in [35] with the specifications from this work. results in the need of extra capacitance at the drainsource of each transistor, as the EPC 2040 only has $70 \mathrm{pF}$ drainsource capacitance [36]. The equations from [35] are shown in (4) and (5), where $I_{o u t}$ and $I_{m}$ are the output current and magnitude of the input current respectively. $V_{\text {out }}$ is the output voltage, $C_{D 1}$ and $C_{D 2}$ are the drain-source capacitances and $\omega$ is the angular frequency of the input signal. Any deviation from soft-switching would result in large switching losses due to the added capacitance, which is undesired. With the added capacitance the input current amplitude is $6.28 \mathrm{~A}$, see (4). In the simulation, it is found that having only the drainsource capacitance of the EPC2040 results in an input current amplitude of $3.14 \mathrm{~A}$, for both half-bridges. The input current amplitude of the full-bridge is $1.57 \mathrm{~A}$, when using only the EPC2040 drain-source capacitance.

\section{B. Component Stress Factors}

$$
\begin{aligned}
S C S F_{i} & =\frac{\sum_{j} W_{j}}{W_{i}} \frac{V_{\max , i}^{2} I_{R M S, i}^{2}}{P^{2}} \\
C C S F_{i} & =\frac{\sum_{j} W_{j}}{W_{i}} \frac{V_{\max , i}^{2} I_{R M S, i}^{2}}{P^{2}}
\end{aligned}
$$

Component stress factors (CSF) are used to evaluate the three topologies and to see which best fits with the specifications. As there are no inductive elements in any of the three topologies, only the semiconductor stress factor (SCSF) and capacitive component stress factor (CCSF) is calculated, see (6) and (7). Here $V_{\text {Max }}$ is the maximum voltage the component experiences and the $I_{R M S}$ is the RMS current running in that component. $W_{j}$ and $W_{i}$ are weighting factors. In this work, each stress factor is weighted equally. $P$ is the output power of the converter. The voltages and currents $V_{M a x}$ and $I_{R M S}$ for each component in each converter are found via the LTspice simulation. The total SCSF ans CCSF for each converter are shown in table III.

TABLE III

CALCULATED COMPONENT STRESS FACTORS OF THE THREE TOPOLOGIES WITHOUT WEIGHTING

\begin{tabular}{|l|r|r|}
\hline Topology: & SCSF & CCSF \\
\hline Class DE Half-Wave low dv/dt Rectifier: & 4.93 & 1.47 \\
\hline Class DE Half-Bridge Rectifier: & 4.93 & 0.74 \\
\hline Class DE Full-Bridge Rectifier: & 2.47 & 0.25 \\
\hline
\end{tabular}

The full-bridge is shown to experiences the fewest stresses on the components. Furthermore, it also has a small amplitude on the output voltage ripple due to the fact that it conducts power in both switching periods. This is also the reason for the lower input current. Based on the CSF analysis the full-bridge topology is chosen.

\section{IMPLEMENTATION}

Choosing the GaN device EPC2040 [36] for synchronous rectification, a GaN compatible gate driver is required. The gate driver also has to have a supply voltage lower than the output voltage of the receiver, as it would, in a commercial product, be supplied from the output. In this work the drive circuitry is supplied from an external source to ensure performance stability in the tests. A block diagram of the fullbridge rectifier is shown in Fig. 5, with the four EPC2040 GaN devices and two LM5113 gate drivers. The voltage sensor and delay compensation for each high side controls the drive signals for the high side in one branch and the low side for the other branch. The delay compensation has been empirically tuned for these exact components. $V_{D}$ represents the external source for the control circuit. The gate resistors $R_{\text {Gate }}$ limit the current which charges the gate capacitances to protect the GaN devices.

The designed full-bridge rectifier circuit is implemented on a printed circuit board (PCB), as shown in Fig. 6, which is optimized for laboratory measurement purposes. For the final 


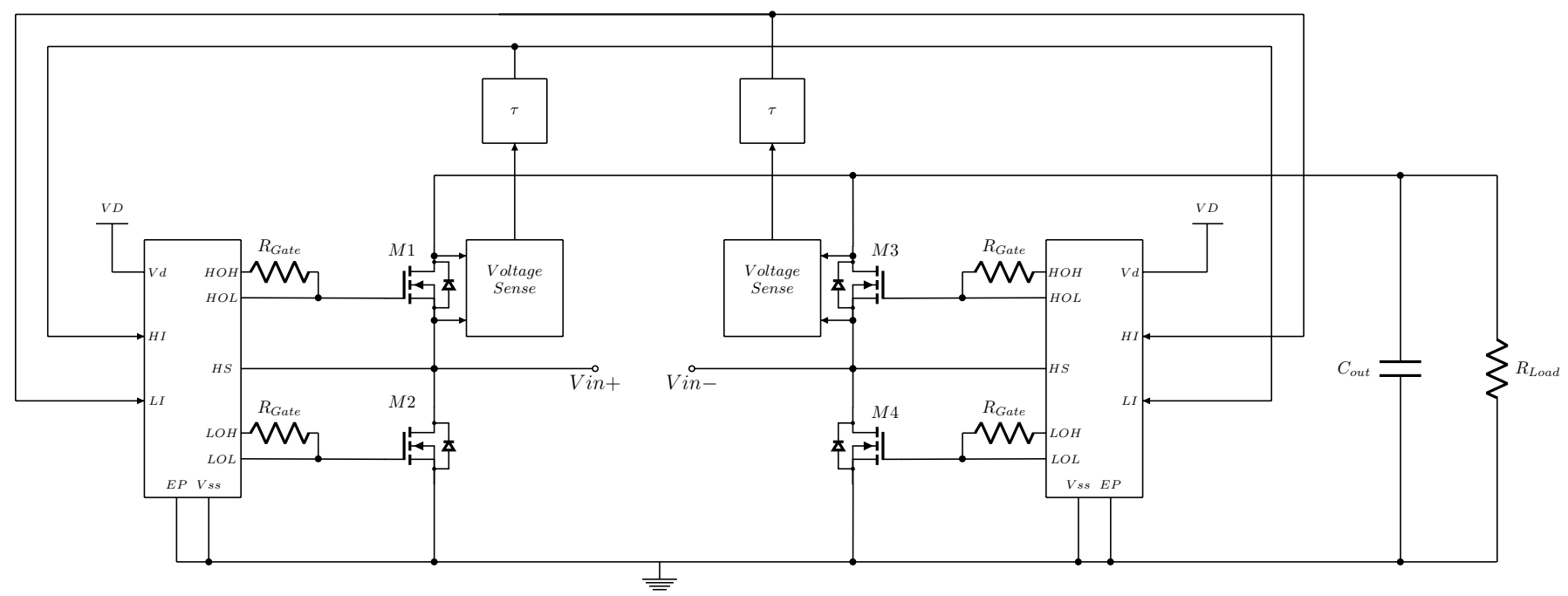

Fig. 5. Block diagram of the proposed Class-DE full-bridge rectifier with synchronous rectification.

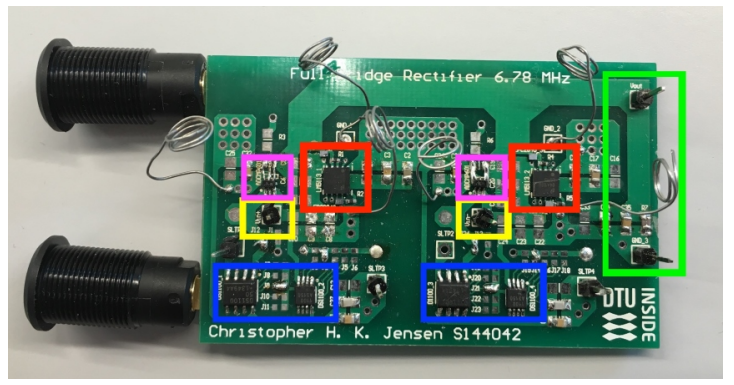

Fig. 6. Prototype PCB. Red: gate driver and GaN devices, blue: feedback, yellow: input, pink: comparator and Green: output.

product design, the circuit can be implemented with higher power density.

\section{A. Impedance Matching}

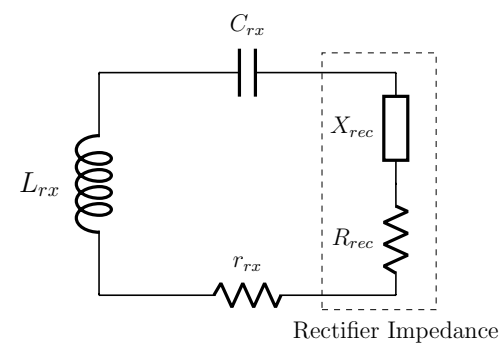

Fig. 7. Equivalent circuit for impedance matching. $L_{r x}$ and $r_{r x}$ are the coil inductance and ac resistance at $6.78 \mathrm{MHz}, \mathrm{C}_{\mathrm{rx}}$ is the matching compensation capacitor. and $\mathrm{X}_{\mathrm{rec}}$ and $\mathrm{R}_{\mathrm{rec}}$ are the rectifiers input reactance and resistance.

$$
\begin{gathered}
j \omega L_{r x}+\frac{1}{j \omega C_{r x}}+j X_{r e c}=0 \\
C_{r x}=\frac{1}{\omega\left(\omega L_{r x}+X_{r e c}\right)}
\end{gathered}
$$

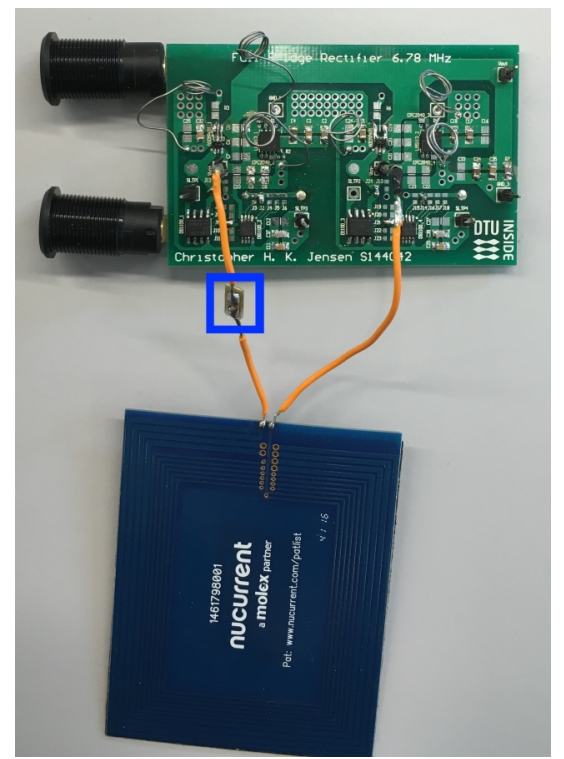

Fig. 8. Prototype PCB with receiver coil connected. Blue: Crx

Impedance matching between the rectifier and the receiver coil is needed to get maximum power transfer at the given operating frequency.

Fig. 7 shows the equivalent impedance circuit of the receiver coil and rectifier. $R_{r e c}$ and $X_{r e c}$ represent the rectifier impedance. $L_{r x}$ and $r_{r x}$ are the inductance and resistance of the receiver coil at the operating frequency of $6.78 \mathrm{MHz}$. At resonance, the reactance should be zero. A compensation capacitor $C_{r x}$ is added in series with the coil and rectifier to achieve resonance, see (8) and (9).

Fig. 8 shows the prototype with the receiver coil, where the green PCB on top is the implemented rectifier, the blue PCB (bottom) is the Rx coil and the blue box in the middle marks $C_{r x}$.

The prototype full-bridge rectifier and receiving coil to- 


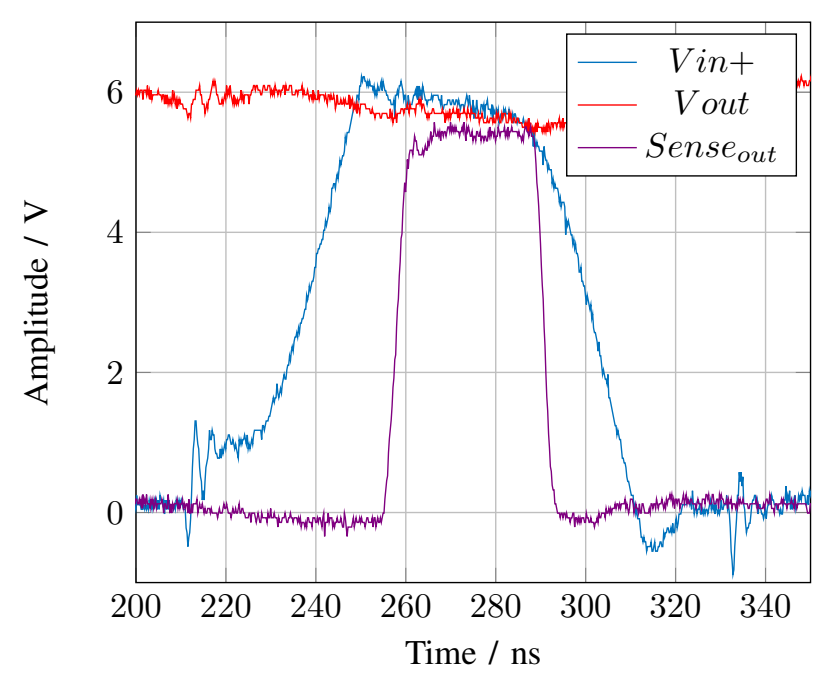

Fig. 9. Measured waveforms. $\mathrm{V}_{\mathrm{in}}+$ and $\mathrm{V}_{\text {out }}$ are the inputs of the voltage sense circuit and Sense $_{\text {out }}$ is the output of the sense circuit

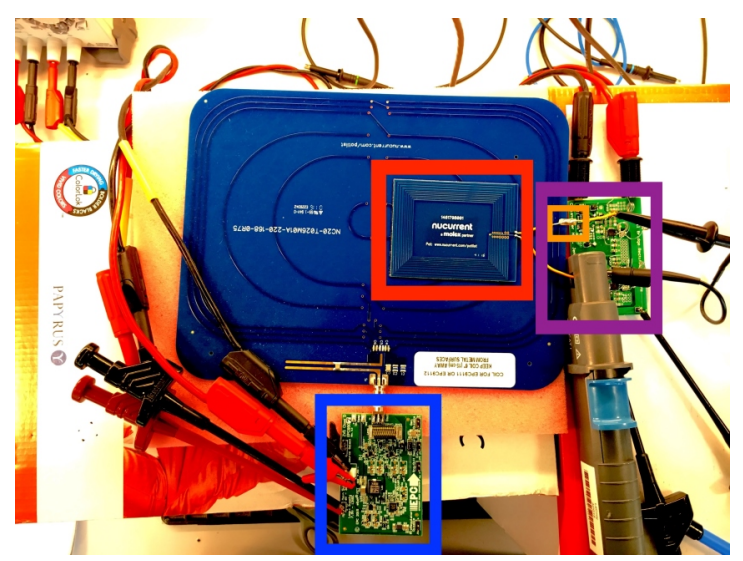

Fig. 10. Measurement setup for the efficiency measurements. Red: receiver coil, blue: inverter, purple: rectifier, orange: compensation capacitor and the large blue plate is the transmitter coil.

gether with the transmitter coil and power amplifier from the EPC9112 demo kit [43] are combined to form a WPT system.

\section{EXPERIMENTAL RESULTS}

The waveforms of the prototype are verified with a LeCroy WavSurfer 104MXs-B, $1 \mathrm{GHz}, 10 \mathrm{GS} / \mathrm{s}$ oscilloscope and for better visualization plotted in Fig. 9 with the help of MATLAB. The waveform drawings in Fig. 9 show the softswitching of the power devices.

Fig. 10 shows the measurement setup for the input power sweep. The red box indicates the placement of the receiving coil on top of the transmitter coil (large blue plate). The blue square in the bottom of the picture shows the power amplifier which drives the transmitter coil. On the right side the rectifier (purple box) and compensation capacitor (orange box) are shown.

The input to output power relation is linear and the efficiency of the full-bridge synchronous rectifier, which is measured with precise multimeters, is above $80 \%$ over a

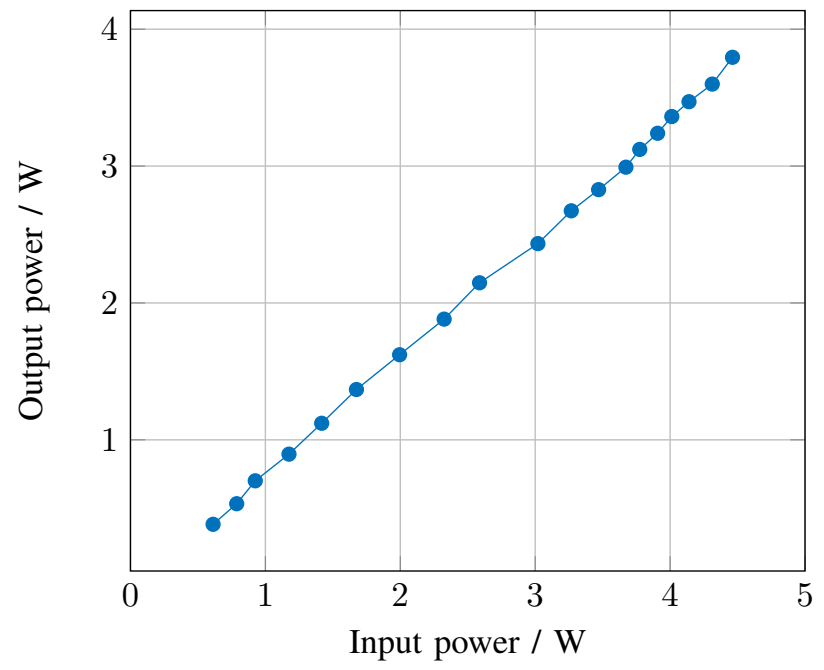

(a)

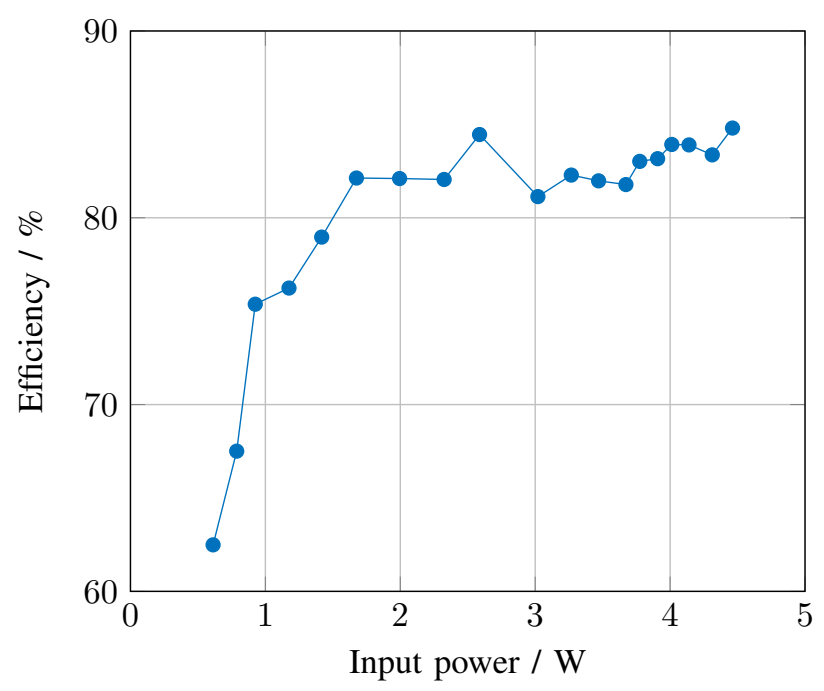

(b)

Fig. 11. The input output power relation (a) and efficiency of the prototype (b)

wide load range. Fig. 11 shows these results. The Rx coil and circuit is arbitrarily placed on top of the Tx coil to resemble a consumer use case in the best possible way.

Afterwards, the distance between the $\mathrm{Tx}$ and $\mathrm{Rx}$ coils is gradually increased by adding multiple $0.75 \mathrm{~cm}$ thick foam bricks as pictured in Fig. 12. Fig. 13 is visualizing the result of this experiment. Again, the placement after each distance change was arbitrary, which explains the roughness of the efficiency plot as a function of distance. The rectifier achieves a peak efficiency of $89 \%$ at $3 \mathrm{~cm}$ distance between Tx and $\mathrm{Rx}$ coils.

\section{CONCLUSiON}

A full-bridge Class-DE receiver circuit for wireless power transfer applications fulfilling the AirFuel standard was analyzed using component stress factors. Low voltage $\mathrm{GaN}$ transistors were compared using figures of merit to silicon 


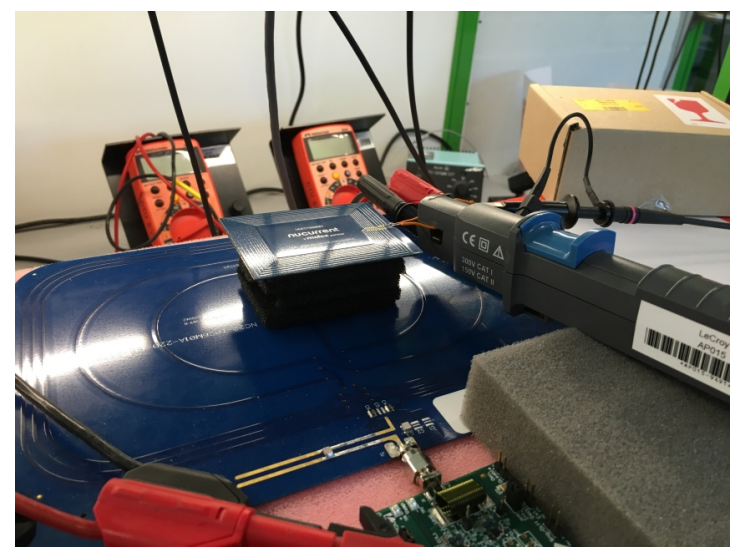

Fig. 12. Experimental setup for hight measurement. There are multiple 0.75 $\mathrm{cm}$ foam bricks between the transmitter and receiver.

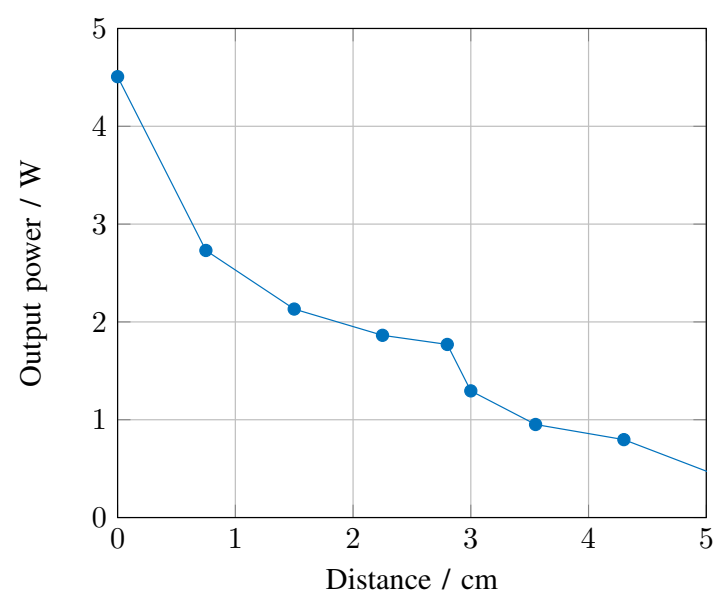

(a)

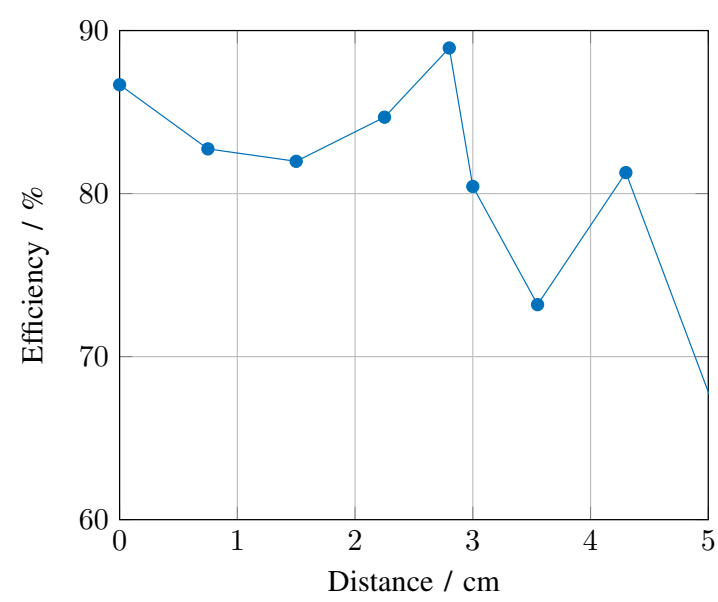

(b)

Fig. 13. Output power vs receiver distance from transmitter (a) and the efficiency of this (b)

transistors and used as synchronous rectifiers. The receiver was realized on a printed circuit board and matched to a 5 $\mathrm{W}$ receiver coil designed for the AirFuel operating standard. Together with an EPC transmitter base station, the receiver was implemented in a wireless power transfer system. The efficiency of the rectifier circuit is well above $80 \%$ over a wide load range. The system was able to transmit power above $1 \mathrm{~W}$ over a distance of $3 \mathrm{~cm}$. Future work would look into optimization of the drive circuit and a way to have the drive circuit powered from either the input or output of the rectifier.

\section{ACKNOWLEDGMENT}

This work is funded partly by the LEDLUM project, which has received funding from the European Union's Horizon 2020 research and innovation programme under grant agreement No. 731466 (This project is an initiative of the Photonics Public Private Partnership.), partly by TinyPower project which is funded by the Danish Innovation Foundation (journal no. 67-2014-1) and partly by the Charger project, supported by EUDP (Energiteknologisk udvikling og demostration) project number 64014-0558. Lastly the author would like to thank Efficient Power Conversion Corporation for their donation of the EPC9112 demo kit for this project.

\section{REFERENCES}

[1] Wireless Power The Qi Wireless Power Transfer System Power Class 0 Specification: Interface Definitions, Wireless Power Consortium, 2016, part. 1 and 2.

[2] A4WP Wireless Power Transfer System Baseline System Specification (BSS) v 1.2.1, Airfuel Alliance, 2014.

[3] R. Pagano, S. Abedinpour, A. Raciti, and S. Musumeci, "Efficiency optimization of an integrated wireless power transfer system by a genetic algorithm," in Applied Power Electronics Conference and Exposition (APEC), 2016 IEEE. IEEE, 2016, pp. 3669-3676.

[4] A. Berger, M. Agostinelli, S. Vesti, J. Á. Oliver, J. A. Cobos, and M. Huemer, "Phase-shift and amplitude control for an active rectifier to maximize the efficiency and extracted power of a wireless power transfer system," in Applied Power Electronics Conference and Exposition (APEC), 2015 IEEE. IEEE, 2015, pp. 1620-1624.

[5] C. Dick, E. Waffenschmidt, A. Krause, and C. Polak, "Qualification of soft-magnetic shielding materials used in inductive wireless power transmission systems," in Applied Power Electronics Conference and Exposition (APEC), 2015 IEEE. IEEE, 2015, pp. 2522-2526.

[6] Y. Zhang, T. Lu, Z. Zhao, F. He, K. Chen, and L. Yuan, "Selective wireless power transfer to multiple loads using receivers of different resonant frequencies," IEEE Transactions on Power Electronics, vol. 30, no. 11, pp. 6001-6005, 2015.

[7] D. Huwig and P. Wambsganß, "Digitally controlled synchronous bridgerectifier for wireless power receivers," in Applied Power Electronics Conference and Exposition (APEC), 2013 Twenty-Eighth Annual IEEE. IEEE, 2013, pp. 2598-2603.

[8] H.-G. Park, J.-H. Jang, H.-J. Kim, Y.-J. Park, S. Oh, Y. Pu, K. C. Hwang, Y. Yang, and K.-Y. Lee, "A design of a wireless power receiving unit with a high-efficiency $6.78-\mathrm{mhz}$ active rectifier using shared dlls for magnetic-resonant a4 wp applications," IEEE Transactions on Power Electronics, vol. 31, no. 6, pp. 4484-4498, 2016.

[9] L. Jiang, D. Costinett, A. Fathy, and S. Yang, "A single stage ac/rf converter for wireless power transfer applications," in Applied Power Electronics Conference and Exposition (APEC), 2017 IEEE. IEEE, 2017, pp. 1682-1688.

[10] J. Feng, Q. Li, and F. C. Lee, "Omnidirecitional wireless power transfer for portable devices," in Applied Power Electronics Conference and Exposition (APEC), 2017 IEEE. IEEE, 2017, pp. 1675-1681.

[11] J. Nadakuduti, M. Douglas, L. Lu, A. Christ, P. Guckian, and N. Kuster, "Compliance testing methodology for wireless power transfer systems," IEEE Transactions on Power Electronics, vol. 30, no. 11, pp. 6264-6273, 2015.

[12] T.-D. Yeo, D. Kwon, S.-T. Khang, and J.-W. Yu, "Design of maximum efficiency tracking control scheme for closed-loop wireless power charging system employing series resonant tank," IEEE Transactions on Power Electronics, vol. 32, no. 1, pp. 471-478, 2017. 
[13] Y. Lu, M. Huang, L. Cheng, W.-H. Ki, U. Seng-Pan, and R. P. Martins, "A dual-output wireless power transfer system with active rectifier and three-level operation," IEEE Transactions on Power Electronics, vol. 32, no. 2, pp. 927-930, 2017.

[14] M. Liu, M. Fu, and C. Ma, "Parameter design for a 6.78-mhz wireless power transfer system based on analytical derivation of class e currentdriven rectifier,' IEEE Transactions on Power Electronics, vol. 31, no. 6, pp. 4280-4291, 2016.

[15] L. Xue and J. Zhang, "Single-stage $6.78 \mathrm{mhz}$ power-amplifier design using high-voltage gan power ics for wireless charging applications," in Applied Power Electronics Conference and Exposition (APEC), 2017 IEEE. IEEE, 2017, pp. 3743-3750.

[16] M. Liu, M. Fu, and C. Ma, "Low-harmonic-contents and high-efficiency class e full-wave current-driven rectifier for megahertz wireless power transfer systems," IEEE Transactions on Power Electronics, vol. 32, no. 2, pp. 1198-1209, 2017.

[17] M. Liu, Y. Qiao, S. Liu, and C. Ma, "Analysis and design of a robust class e2 dc-dc converter for megahertz wireless power transfer," IEEE Transactions on Power Electronics, vol. 32, no. 4, pp. 2835-2845, 2017.

[18] R. Bonache-Samaniego, C. Olalla, L. Martínez-Salamero, and D. Maksimović, "6.78 mhz self-oscillating parallel resonant converter based on gan technology," in Applied Power Electronics Conference and Exposition (APEC), 2017 IEEE. IEEE, 2017, pp. 1594-1599.

[19] D. Ahn, S. Kim, S.-W. Kim, J. Moon, and I. Cho, "Wireless power transmitter and receiver supporting 200-khz and 6.78-mhz dual-band operation without magnetic field canceling," IEEE Transactions on Power Electronics, vol. 32, no. 9, pp. 7068-7082, 2017.

[20] D. Ahn and P. P. Mercier, "Wireless power transfer with concurrent 200-khz and 6.78-mhz operation in a single-transmitter device," IEEE Transactions on Power Electronics, vol. 31, no. 7, pp. 5018-5029, 2016.

[21] J. A. Santiago-González, K. M. Elbaggari, K. K. Afridi, and D. J. Perreault, "Design of class e resonant rectifiers and diode evaluation for vhf power conversion," IEEE Transactions on Power Electronics, vol. 30, no. 9, pp. 4960-4972, 2015.

[22] M. Kline, I. Izyumin, B. Boser, and S. Sanders, "Capacitive power transfer for contactless charging," in Applied Power Electronics Conference and Exposition (APEC), 2011 Twenty-Sixth Annual IEEE. IEEE, 2011, pp. 1398-1404.

[23] C. Zhao, Z. Wang, J. Du, J. Wu, S. Zong, and X. He, "Active resonance wireless power transfer system using phase shift control strategy," in Applied Power Electronics Conference and Exposition (APEC), 2014 Twenty-Ninth Annual IEEE. IEEE, 2014, pp. 1336-1341.

[24] R. Mai, Y. Liu, Y. Li, P. Yue, G. Cao, and Z. He, "An activerectifier-based maximum efficiency tracking method using an additional measurement coil for wireless power transfer," IEEE Transactions on Power Electronics, vol. 33, no. 1, pp. 716-728, 2018.

[25] C. H. K. Jensen, "Implementation of a power converter in a wireless power transfer system," Bachelor Thesis, Technical University of Denmark, July 2017.
[26] Y. Lu and W.-H. Ki, "A $13.56 \mathrm{mhz}$ cmos active rectifier with switchedoffset and compensated biasing for biomedical wireless power transfer systems," IEEE transactions on biomedical circuits and systems, vol. 8, no. 3, pp. 334-344, 2014.

[27] K. Yogosawa, H. Shinohara, and K. Miyaji, "A $13.56 \mathrm{mhz} c \mathrm{mos}$ active diode full-wave rectifier achieving zvs with voltage-time-conversion delay-locked loop for wireless power transmission," in Design Automation Conference (ASP-DAC), 2017 22nd Asia and South Pacific. IEEE, 2017, pp. 27-28.

[28] Y. Sun, C.-j. Jeong, S.-k. Han, and S.-g. Lee, "A high speed comparator based active rectifier for wireless power transfer systems," in Intelligent Radio for Future Personal Terminals (IMWS-IRFPT), 2011 IEEE MTT-S International Microwave Workshop Series on. IEEE, 2011, pp. 1-2.

[29] S. Aldhaher, P. C.-K. Luk, K. E. K. Drissi, and J. F. Whidborne, "Highinput-voltage high-frequency class e rectifiers for resonant inductive links," IEEE Transactions on Power Electronics, vol. 30, no. 3, pp. 1328-1335, 2015.

[30] M. K. Kazimierczuk and D. Czarkowski, Resonant power converters. John Wiley \& Sons, 2012.

[31] A. Knott, T. M. Andersen, P. Kamby, J. A. Pedersen, M. P. Madsen, M. Kovacevic, and M. A. Andersen, "Evolution of very high frequency power supplies," IEEE Journal of Emerging and Selected Topics in Power Electronics, vol. 2, no. 3, pp. 386-394, 2014.

[32] M. P. Madsen, A. Knott, and M. A. Andersen, "Very high frequency half bridge dc/dc converter," in Applied Power Electronics Conference and Exposition (APEC), 2014 Twenty-Ninth Annual IEEE. IEEE, 2014, pp. 1409-1414.

[33] M. Madsen, A. Knott, and M. A. Andersen, "Low power very high frequency switch-mode power supply with $50 \mathrm{v}$ input and $5 \mathrm{v}$ output," IEEE Transactions on Power Electronics, vol. 29, no. 12, pp. 6569-6580, 2014.

[34] D. C. Hamill, "Class de inverters and rectifiers for dc-dc conversion," in Power Electronics Specialists Conference, 1996. PESC'96 Record., 27th Annual IEEE, vol. 1. IEEE, 1996, pp. 854-860.

[35] K. Fukui and H. Koizumi, "Analysis of half-wave class de low dv/dt rectifier at any duty ratio," IEEE Transactions on Power Electronics, vol. 29, no. 1, pp. 234-245, 2014.

[36] EPC2040 - Enhancement Mode Power Transistor, Efficient Power Conversion Corporation, 2017, datasheet.

[37] Sil050X, Vishay Siliconix, 112010.

[38] SiUD412ED, Vishay Siliconix, 8 2016, rev D.

[39] Si4838DY, Vishay Siliconix, 2 2009, rev D.

[40] Si2342DS, Vishay Siliconix, 2 2009, rev D.

[41] DMN1260UFA, Diodes Incorporated, 2 2015, rev 3.

[42] Y. Nour, A. Knott, and I. H. Jørgensen, "Investigating enhancement mode gallium nitride power fets in high voltage, high frequency soft switching converters," 2016.

[43] Demonstration System EPC9112 Quick Start Guide, Efficient Power Conversion Corporation, 2017. 